\title{
AS RÓTULAS MACHADIANAS: HABITAÇÃO POPULAR, ESTRANGEIRISMO E MODERNIZA- ÇÃO NO RIO DE JANEIRO DA SEGUNDA ME- TADE DO SÉCULO XIX
}

\section{THE LATTICES OF ASSIS: POPULAR HOUSING, FOREIGNNESS AND MODERNIZATION IN RIO DE JANEIRO OF THE SECOND HALF OF THE NINETEENTH CENTURY}

\author{
Elson Granzoto Junior \\ Michelle Carolina de Britto \\ Patrícia Moreira Nogueira \\ Tuanny Folieni Antunes Lanzellotti ${ }^{1}$
}

Resumo: Partindo da literatura machadiana, o presente artigo tem por objetivo refletir sobre o processo de urbanização e modernização da cidade do Rio de Janeiro, entre as últimas décadas do século XIX e início do século XX. Ambientadas na capital carioca, as obras de Machado de Assis aqui recortadas - focadas em contos, crônicas e romances - ecoavam uma cidade que aos olhos do escritor era mais humana e que transparecia como "um pano de fundo onipresente". A análise desses escritos possibilitou, assim, a compreensão das novas acepções do modo de morar, das transformações ocorridas nas relações sociais e no espaço urbano que estava se constituindo e, ainda, do posicionamento crítico de Assis diante da política urbana do período. Como intencionamos apontar, a crítica machadiana se caracterizava por um saudosismo ao tempo do Imperador que possibilita ao leitor um contato com a cidade por meio de rótulas que escondiam, ou mesmo, não deixavam enxergar as mudanças de seu entorno.

Palavras-chave: Urbanização; Rio de Janeiro; Machado de Assis; Literatura.

${ }^{1}$ Graduandos em História pela Universidade Federal de São Paulo (UNIFESP). Agradecemos a colaboração da colega Ana Carolina Rocha durante o processo de levantamento de dados acerca das obras analisadas neste artigo. 
Abstract: By the light of Assis's literature, this article aims to reflect on the process of urbanization and modernization in Rio de Janeiro. Set in Rio de Janeiro in the late nineteenth century and early twentieth century, the work of Machado de Assis analyzed here - focused on short stories, essays and novels - echoed a city that in the writer's eyes was more human and which appeared to be "an omnipresent backdrop". The analysis of Machado's works enabled us to understand the meanings of the new way of living, the changes that have happened in the social relations in urban space, and also the critical positioning of Assis with regards to urban policy of the concerned period. How we intend pointing, Assis's criticism was characterized by a nostalgia for the time of the Emperor which allows the reader to be in touch with the city by means of the lattice that hid, or even, did not let see the transformations in their surrounding.

Keywords: Urbanization; Rio de Janeiro; Machado de Assis; Literature.

\section{Introdução}

Os modos de morar e o urbanismo nas obras de Machado de Assis são as temáticas, de modo amplo, sobre as quais este trabalho discorre. Refletindo sobre de que maneira é possível analisar as transformações ocorridas na cidade do Rio de Janeiro nas últimas décadas do século XIX e nos anos iniciais do século XX, sob o viés da literatura machadiana. Recortes, porém, são necessários e, neste caso, as próprias fontes analisadas recortaram os aspectos que iremos abordar ao longo do artigo. Utilizaremos, nesta análise, duas crônicas, um romance e contos escritos por Machado de Assis a partir da década de 1870 até o final do século XIX. Empregaremos no trabalho alguns contos avulsos e outros pertencentes às seguintes coletâneas: Contos Fluminenses (1870), Papéis avulsos (1882), Histórias sem data (1884), Varias histórias (1896) e Páginas recolhidas (1899). Além disso, utilizaremos excertos 
do romance Esaú e Jacó (1904) e das crônicas Bons dias! (1888-1889) e A Semana (1892-1900).

O recorte geográfico escolhido foi a capital do Rio de Janeiro e mais especificamente, algumas áreas centrais da cidade percorridas e descritas por Assis em suas obras. O Rio de Janeiro no período por nós analisado sofreu imensas mudanças, como a grande expansão de trens e bondes a partir da década de 1870 ou a onda de demolições de cortiços da década de 1890, empreendida pelo prefeito Barata Ribeiro e que inicia, segundo Mauricio de A. Abreu, "um processo de intervenção direta do Estado sobre a área central da cidade, que viria a se intensificar sobremaneira a partir do início do século" (Abreu, 2006: p. 50). Esse, portanto, foi certamente um período de intensas transformações no espaço urbano e nas concepções acerca dos modos de morar na cidade. Nesse sentido, ao longo do trabalho pretendemos abordar algumas dessas situações, sejam elas explicitamente citadas por Machado de Assis ou ainda, pouco mencionadas.

Em um primeiro momento, apontaremos alguns aspectos centrais para o entendimento do espaço nas obras de Assis, partindo da ideia do ambiente como uma extensão de suas personagens. Em seguida, trabalharemos a questão na habitação popular e o estranhamento das personagens em relação a tais espaços. Em um terceiro momento, refletiremos sobre como as alterações ocorridas no Rio de Janeiro foram percebidas por Machado de Assis, atentando para a questão dos transportes e de elementos como a rótula - ou seja, antigas grades coloniais de madeira, dispostas em janelas e portas e que permitiam a 
entrada de luz e ar por meio de ripas entrecruzadas -, que sobreviveram às novas concepções de espaço, sendo um possível indício do diálogo entre o tradicional e a modernidade emergente.

Esperamos aqui, apresentar um pouco do Rio de Janeiro que Machado de Assis diariamente contemplava. Segundo John Gledson, o crítico literário especialista na obra de Machado, é possível um entendimento mais amplo da obra de Assis a partir do "conhecimento mais ou menos detalhado da geografia física e (sobretudo) social da cidade" (Carrer; Gledson e Menezes, 1999: 11). De encontro a essa perspectiva, talvez seja possível também compreender melhor qual é o espaço urbano configurado nesse final do século XIX e primórdios do século XX na cidade do Rio de Janeiro por meio dos textos de Machado de Assis.

\section{O Rio enviesado: o ambiente como extensão das personagens}

Ao pensarmos sobre a temática da habitação e ocupação do território a partir das obras de Machado de Assis, nos deparamos com descrições pontuais e curtas sobre os ambientes em que suas personagens agem. Uma crítica literária mais clássica sobre a obra machadiana interpretou essa opção como uma falta de sensibilidade do autor em relação ao habitat brasileiro ou, ainda, como um alinhamento de Machado com a tendência europeizante que se intensificava nos debates políticos em fins do século XIX (Santos, 2000). ${ }^{2}$ Em tal

${ }^{2}$ Essa tendência de análise sobre o ambiente em Machado se cristalizou na crítica literária a partir de Silvio Romero na virada do século XX até os anos de 
perspectiva, para suprir essa deficiência em sua obra, o escritor recorreria a personagens extremamente complexas psicologicamente, sendo os contos tomados em grande medida por suas reflexões.

Roger Bastide em um artigo intitulado Paisagista Machado discorda totalmente dessa visão e foi um dos primeiros a afirmar que as descrições pontuais feitas por Machado apresentavam versões muito mais complexas e fidedignas do Rio de Janeiro naquele fim de século, descrições destituídas de exotismo e exagero (Bastide, 1940). Partindo da constatação de Bastide, o historiador Fabio Muruci defendeu que as descrições do espaço em Machado partiam da ótica de suas personagens e estavam intrinsecamente relacionadas com suas atitudes e mentalidades. O espaço vivido tornou-se, assim, uma extensão das personalidades marcantes nas obras. A presença de narradores personagens nos contos e alguns romances ajuda a reforçar tal perspectiva:

O que leitores de várias gerações não teriam percebido é que esses narradores não são confiáveis. Machado realmente acentua o subjetivismo com que os narradores veem, julgam e contam os acontecimentos, mas não propriamente para defender $o$ relativismo como filosofia. $\mathrm{O}$ acento machadiano seria mais político e histórico do que filosófico. Machado não é um relativista e sim denuncia o relativismo, ou mais precisamente o arbitrarismo, de suas personagens, demonstrando o funcionamento cotidiano de suas mentes quando confrontadas com situações melindrosas [...] (Santos, 2003: 179-80).

1970. 
Defendemos, portanto, não um Machado frio e avesso às transformações políticas e sociais de finais do século XIX no Brasil, mas sim uma presença crítica no que concerne às práticas de uma elite que ansiava por modernizações sem, porém, alcançar mudanças importantes na ordem política e social vigente. A partir de algumas crônicas, da análise das descrições presentes nos contos selecionados e da territorialização percorrida pelas personagens nessas obras, podemos encontrar um Rio de Janeiro muito diverso e ambíguo frente a um desejo cada vez maior de torná-lo uma cidade moderna.

Em relação a tal questão. John Gledson, afirmou que: "Para Machado, o Rio era sobretudo uma realidade humana" (1999: 12). Ou seja, a descrição de algum local ou ambiente da cidade só faria sentido se relacionado com acontecimentos comentados por Machado em suas crônicas ou vivenciados por suas personagens. Ainda para o autor: "Machado tem suas restrições a esta visão convencional 'para inglês ver' do Rio de Janeiro, que ignora a realidade humana da cidade" (Idem). Nesse ponto, Gledson se refere às descrições comuns nas obras românticas que desconsideravam a múltipla presença de tipos sociais no ambiente carioca. Assim, percebe-se que nenhuma descrição em Assis foi feita com objetivo estético ou ideológico, mas para conceber noções de realismo e pertencimento - ou a falta dele - à suas personagens. ${ }^{3}$

\footnotetext{
${ }^{3}$ Nesse ponto Gledson demonstra a sátira de Machado ao descrever o percurso de Bentinho entre sua casa e o colégio, em Dom Casmurro. Em distância tão curta, Bentinho desenvolve emoções que sugerem uma imensa separação espacial de sua família. (1999: 12).
} 


\section{Habitação popular: estrangeirismo no espaço}

Em Esaú e Jacó - romance de 1904, ambientado por volta das décadas de 1860 a 1890 - na subida de Natividade e sua irmã ao Morro do Castelo, para uma consulta a certa vidente, podemos encontrar os primeiros indícios desse olhar enviesado das personagens sobre sua agência no ambiente. Não habituadas a caminhar por ladeiras e ruas mal calçadas, as nobres senhoras causam riso aos transeuntes típicos desse local: de clérigos a escravos, alguns chegam inclusive a adivinhar que tão distintas pessoas andando naquele ambiente destinavam a se consultar com a famosa Cabocla do Morro do Castelo (Assis, 2012a: 02). A descrição da paisagem do morro é feita a partir do caminhar das personagens, como se caminhássemos com elas:

O íngreme, o desigual, o mal calçado da ladeira mortificavam os pés às duas pobres donas. Não obstante, continuavam a subir, como se fosse penitência, devagarinho, cara no chão, véu para baixo. A manhã trazia certo movimento; mulheres, homens, crianças que desciam ou subiam, lavadeiras e soldados, algum empregado, algum lojista, algum padre, todos olhavam espantados para elas, que aliás vestiam com grande simplicidade; mas há um donaire que se não perde, e não era vulgar naquelas alturas. A mesma lentidão do andar, comparada à rapidez das outras pessoas, fazia desconfiar que era a primeira vez que ali iam (Assis, 2012a:02).

Observa-se que todo o foco da cena está no estranhamento provocado pelas senhoras ao embrenharem-se no local, algo notável por meio de suas vestimentas até por sua forma de andar, demonstrando o contraste social presente na época no que diz respeito às vivências no Morro do Castelo. Até mesmo o calçamento das vielas provoca 
desconforto nas damas nobres, uma vez que elas, ao adentrarem um espaço social tão distinto do habitual, saem de sua zona de conforto. Parece possível aferir ainda, que as senhoras descritas vivenciassem um desconforto também em relação a um tempo que se passou, uma vez que as pessoas com um novo andar rápido, por exemplo, destoavam de um modelo de tempo mais lento representado por ambas mulheres.

A constituição do espaço urbano como zona de conforto e um tempo deslocado para determinados grupos sociais é um tema constante também nas descrições que Assis faz nos contos. Em A cartomante (1884), a ida de Camilo a seu encontro é descrita com rapidez, numa tentativa, tanto do narrador como do autor da ação, de esconderem o que iam fazer em tal local: "Deu por si na calçada, ao pé da porta; disse ao cocheiro que esperasse, e rápido enfiou pelo corredor, e subiu a escada. A luz era pouca, os degraus comidos dos pés, o corrimão pegajoso; mas ele não viu nem sentiu nada. Trepou e bateu" (Assis, 2002: 156). A rapidez com que Camilo deseja vencer o ambiente é tamanha que sequer percebe (ou talvez naturalize) a insalubridade da moradia popular.

Um dos casos mais emblemáticos para nossa análise está em $O$ espelho. Quando após passar férias numa fazenda de escravos no interior o jovem recém-nomeado alferes vê os escravos da família fugirem pelas ruas do Rio de Janeiro, sua personalidade se abala de tal forma que ele passa a encontrar conforto apenas diante de um espelho com as vestimentas de alferes. Diante da perda dos símbolos máximos de distinção social na época - a posse de escravos - a personagem se apega ao cargo militar (Assis, 1994: 347). 
Esse distanciamento não gera somente um desconforto nas personagens. É como se elas fossem estrangeiras dentro da própria cidade. Nesse aspecto, Machado mostra como suas personagens estavam enclausuradas em seus próprios ambientes e visões de mundo, mesmo em uma cidade que ainda não possuía diferenciação territorial ampla, como o Rio de fins do XIX. (Carrer, et. tal., 1999: 12). Voltando às senhoras que visitam o Morro do Castelo em Esaú e Jacó, podemos compreender a ironia que Machado faz defendendo essa perspectiva:

Era a primeira vez que as duas iam ao Morro do Castelo. Começaram de subir pelo lado da rua do Carmo. Muita gente há no Rio de Janeiro que nunca lá foi, muita haverá morrido, muita mais nascerá e morrerá sem lá pôr os pés. Nem todos podem dizer que conhecem uma cidade inteira. Um velho inglês, que aliás andara terras e terras, confiava-me há muitos anos em Londres que de Londres só conhecia bem o seu clube, e era o que lhe bastava da metrópole e do mundo. Natividade e Perpétua conheciam outras partes, além de Botafogo, mas o Morro do Castelo, por mais que ouvissem falar dele e da cabocla que lá reinava em 1871, era-lhes tão estranho e remoto como o clube (Assis, 2012a: 1-2).

Fica clara a relação entre ambiente e vida das personagens nessas obras. Nada há de alienação do autor quanto às ambiguidades inerentes à cidade. Para fundamentar nossa hipótese, nesse ponto, talvez seja interessante apresentar as posições de Assis sobre determinados temas comentados em crônicas publicadas pelo autor ao longo das últimas décadas do século XIX. A predominância de personagens da classe aristocrática ou enriquecida do Império nas obras poderia levar-nos a inferir que Machado de Assis não se interessava pela presença das classes populares e apoiava as medidas tomadas pelos governos imperial 
e republicano no sentido de reprimir e disciplinarizar sua atuação no espaço urbano.

Por outro lado, essa impressão é matizada ao considerarmos elementos fundamentais da obra machadiana como sua latente ironia. Isso pode ser evidenciado por meio das descrições dos espaços, marcadas pela visão estereotipada e limitada que aquelas personagens possuíam sobre o meio no qual viviam. Espaço esse que, embora não espacialmente dividido, era segregado pela agência dessas personagens no meio urbano.

Foi nas crônicas que Machado discorreu mais diretamente sobre os temas que envolviam a regulação e modernização da cidade. Essa modernização pode ser encarada a partir da entrada de diversas teorias científicas no Brasil e sua disseminação entre as elites ascendentes. $\mathrm{Na}$ série Bons dias!, constatamos intensas críticas aos discursos científicos que vinham ganhando espaço. Segundo Assis, alegando que algo era ciência poderíamos justificar quaisquer atitudes:

Seriam os meus primeiros estudos práticos; mas imagine-se o que poderia sair de tais estreias. Casas de penhores, ourives, joalherias. Subia ainda; ia aos tribunais ganhar causas, ia às câmaras legislativas obter votos, ia ao governo, ia a toda parte. De cada negócio (e nisto poria o maior apuro científico), compunha uma longa e minuciosa memória, expondo as observações feitas em cada paciente, a maior ou menor docilidade, o tempo, os fenômenos de toda a espécie; e por minha morte deixaria esses escritos ao Estado. (Assis, 2012b: 23).

Ao praticar diversos atos criminosos com o auxilio da hipnose, o narrador da crônica crê que estaria fazendo grande serviço ao Estado, 
uma vez que tais atos são imbuídos do "maior apuro científico". Ainda em Bons dias!, Machado empreende diversas críticas à forma como o espiritismo estava sendo pregado e disseminado entre as elites da corte:

Os espiritistas brasileiros acabam de dar um golpe de mestre. Apareceu por aqui um médium, Dr. Slade é o seu nome, com a fama de ser prodigioso. A Federação espírita Brasileira nomeou uma comissão para estudar os fenômenos de escritura direta sobre ardósias e outros efeitos físicos produzidos com o médium. Pois, senhores, não achou que o homem valesse a fama; declarou que os trabalhos ficaram muito abaixo do que esse mesmo médium conseguiu na Inglaterra, França, Alemanha, Estados Unidos e Austrália. É verdade que a própria Federação explica a diferença. Todos os que estudam os fenômenos espíritas (diz ela) conhecem que as mediunidades estão sujeitas a esses eclipses."E noutro lugar: Sabem todos que os invisíveis não estão servilmente à nossa disposição."(Assis, 2012b: 13).

Essa representação do espiritismo também esteve presente em Esaú e Jacó. Ao saber das previsões da Cabocla pela esposa, Santos o mais rápido possível recorre a seu mestre espírita para saber se as previsões são confiáveis ou não (Assis, 2012a: 15). A partir de sua afirmativa, Santos passou a refletir cientificamente sobre a briga espiritual de seus filhos. Notamos que as críticas de Machado não se referiam especificamente a determinadas teorias, mas na forma como elas estavam sendo disseminadas e utilizadas como prerrogativa de progresso intelectual pelas elites cariocas. O próprio contraponto espacial entre "religião científica" e "crendice popular" é feito em Esaú e Jacó pela presença das descrições da casa da Cabocla e do doutor Plácido, situadas no Morro do Castelo e na Rua Senador Vergueiro, respectivamente. A partir desse momento, portanto, é possível refletir 
sobre de que maneira o "popular" e o "tradicional", o "antigo" e o "moderno" viriam a dialogar e a se confrontar em meio à configuração do espaço urbano na cidade do Rio de Janeiro.

\section{Cidade de rótulas: $o$ antigo sobrevive ao modernizante}

A população do Rio de Janeiro no decorrer do século XIX presenciou importantes mudanças ocorridas na cidade, as quais influenciaram as formas de vida, relacionadas também às transformações urbanas e aos modos de morar. A expansão dos transportes coletivos é um exemplo, dada a sua importância, já que se pode analisar as mudanças da cidade do Rio de Janeiro no século XIX em dois períodos distintos, a fase anterior ao aparecimento dos bondes e trens (por volta da década de 1860) e o período imediatamente posterior (Abreu, 2006: 37).

A mobilidade torna-se, assim, uma relevante diferenciação para com o deslocamento espacial a partir de 1870 , devido à introdução do bonde de burro e do trem a vapor, a mobilidade que antes era privilégio de poucos se expandiu, fazendo com que a cidade crescesse em diferentes direções. Como mencionou Maurício de A. Abreu:

Controlados em grande parte pelo capital estrangeiro, trens e bondes tiveram um papel indutor diferente no que toca à expansão física da cidade. Os primeiros passaram a servir áreas ainda fracamente integradas à cidade, que se abriram então àqueles que podiam se dar ao luxo de morar fora da área central mas não podiam arcar com os custos, já elevados, dos terrenos da Glória, Botafogo ou Tijuca; os bondes permitiram o êxodo cada vez maior dos que podiam arcar com esse ônus, mas mantinham- 
se no centro por falta de meio de transporte rápido e regular (Abreu, 2006: 43).

É perceptível, portanto, como o surgimento dos transportes coletivos trouxe à cidade do Rio de Janeiro intensas transformações urbanas. Ao refletir sobre essa temática e a literatura de Machado de Assis, principalmente em relação aos contos, nos surpreendemos com a ausência de referências aos bondes e trens, uma vez que não encontramos excertos sobre o surgimento e relevância de tais meios de transporte para o período.

Essa problemática foi, de certo modo, um dos pontos que nos fizeram pensar sobre a postura de Machado de Assis em relação à expansão urbana que acontecia nesse momento de maneira desenfreada, pois, é improvável que Assis como crítico de sua época não reconhecesse a forma pela qual os transportes coletivos influenciaram as modificações na cidade do Rio de Janeiro. As discussões em torno desse assunto abrem margem, portanto, para pensarmos se há, nas obras machadianas e no pensamento do autor, uma relutância perante as transformações que estão ocorrendo no momento, em uma contraposição entre o novo e antigo Rio de Janeiro. Como nos diz John Gledson:

A visão machadiana não é sentimental, mas isto não quer dizer que seja indiferente. $\mathrm{O}$ que pode parecer conservadorismo ou saudosismo no seu amor pelo Rio de Janeiro em que viveu e cujo crescimento acompanhou é, acho, um desejo de conservar uma parte importante da dimensão humana da qual Machado se lembra no topo do Morro do Castelo. Isto torna-se mais evidente nas crônicas que escreveu na década de 1890, quando faltava 
pouco para o Bota-abaixo, a primeira mudança radical á qual a cidade foi submetida, e que sobrepôs o traçado reto da avenida Central (hoje Rio Branco) ao labirinto de ruas e becos estreitos do velho Centro. Para Machado, a verdadeira artéria da cidade é a rua do Ouvidor, onde parece conhecer cada loja, e onde as notícias, em forma de boato, correm de um extremo a outro da rua, e de lá pela cidade afora (Carrer, et. tal., 1999: 17).

Em meio à modernização urbana pela qual a cidade do Rio de Janeiro passava, também havia as transformações na habitação. Nos contos de Assis encontramos diferentes descrições em relação à moradia, principalmente dos espaços internos das casas, em que ele nos garantiu a possibilidade de pensar sobre as diversas formas de morar e os espaços constitutivos da moradia. Segundo Rafael Alves Pinto Junior:

[...] Machado de Assis dizia, pelo personagem Brás Cubas, que a casa resgatava tudo: ' $\mathrm{O}$ mundo vulgar terminaria à porta - e dali para dentro era o infinito, um mundo eterno, superior, excepcional, sem leis, sem instituições, uma só afeição [...] - a unidade moral de todas as coisas pela exclusão das que me eram contrárias' (Pinto Junior, 2009: 122).

No conto Cantiga Velha de 1883, Machado descreve alguns dos espaços internos da casa em que a história é contada, no qual é possível perceber como os espaços eram distribuídos e como existia, de tal modo, uma especialização das funções. O excerto a seguir nos elucida sobre de que maneira os espaços eram utilizados dentro de uma moradia plurifuncional:

O dono da casa dera-nos um bom jantar. Fomos os quatro, no fim para junto de uma janela, que abria para um dos lados da chácara. Posto estivéssemos no verão, corria um ventozinho fresco, e a temperatura parecia impregnada das últimas águas. Na sala de 
frente, dançava-se a polca; noutra sala jogava-se o voltarete. Nós, como digo, falávamos de cantigas populares. (Assis, 1994).

Também encontramos nos contos descrições de moradias que ainda contavam com a presença de rótulas, mesmo que o Rio de Janeiro neste período estivesse passando por um processo de modernização cuja intenção era substituir os resquícios coloniais, refletida também na arquitetura. $\mathrm{O}$ conto Noite de Almirante apresentou passagens em que as rótulas aparecem, em frases como "A casa é uma rotulazinha escura, portal rachado do sol [...]" (Assis, 2002: 132) e "Depois foi ao espelho de pataca, suspenso na parede, entre a janela e a rótula [...]" (Assis, 2002: 136).

Essa questão nos leva a conjecturar sobre qual seria o Rio de Janeiro na visão de Machado de Assis, espectador de tais transformações, que visavam modernizar e trazer o progresso. Ainda que o autor fosse um republicano, talvez seja possível encontrar uma relutância perante a expansão desenfreada. Na crônica A Semana (18921900), por exemplo, Machado de Assis, movimentou-se entre as descontinuidades de seu tempo e as permanências do tempo do imperador. A estrutura comparativa, entre o passado e presente, atribuiu uma cadência rítmica a crônica e transmitiu ao leitor a sensação de mudança abrupta da sociabilidade, da organização espacial e dos modos de morar.

Assis, é claro, não estava alheio às transformações que transcorreram no Rio de Janeiro oitocentista, pelo contrário ao não 
mencioná-las o escritor voltou-se para a consolidação da "simpleza antiga"4 que pode ser percebida na espacialidade das habitações.

Espaços interno e externo das moradas, combinados, associam práticas artesanais e fabris, numa dialética de ritmos - tempos e movimentos- vários, lembrando que toda reprodução da cultura inclui sua transformação. Nessa perspectiva, os chamados 'efeitos da urbanização' sobre o cotidiano são enganosos; erra quem pensa que o Rio, ao longo do século XIX, não evolui além de um 'padrão colonial' de sucessivas alterações urbanas de pouca monta (Costa, 2007).

Pode-se notar um pouco dessa percepção sobre a confluência de "Rios de Janeiro" na obra de Machado de Assis no que tange a urbanização do território fluminense no perímetro espacial pelo qual suas obras perpassaram. A ação de suas personagens está concentrada entre os Morros do Senado, do Castelo, de São Bento, do Livramento e da Providência, zona urbanizada e na qual se destaca, consagrada na literatura brasileira, a Rua do Ouvidor, como vemos nos mapas abaixo:

${ }^{4}$ Expressão de Machado de Assis e presente no artigo de Suely Gomes Costa. 


\section{MAPA 01 - Perímetro da Narrativa Machadiana}

AUTOR DESCONHECIDO. Nova planta da cidade do Rio de Janeiro. Rio de Janeiro: A'venda em casa dos editores, E. \& H. Laemmert, 1867. 1 mapa : col., 41 x $54 \mathrm{~cm}$. Escala não especificada. Disponível em: <http://memory.loc.gov/cgi-bin/query/h?ammem/gmd:@field\% 28NUMBER+ @band \%28g5404r+br000055\%29\%29>. Acesso em: 22 out. 2012.

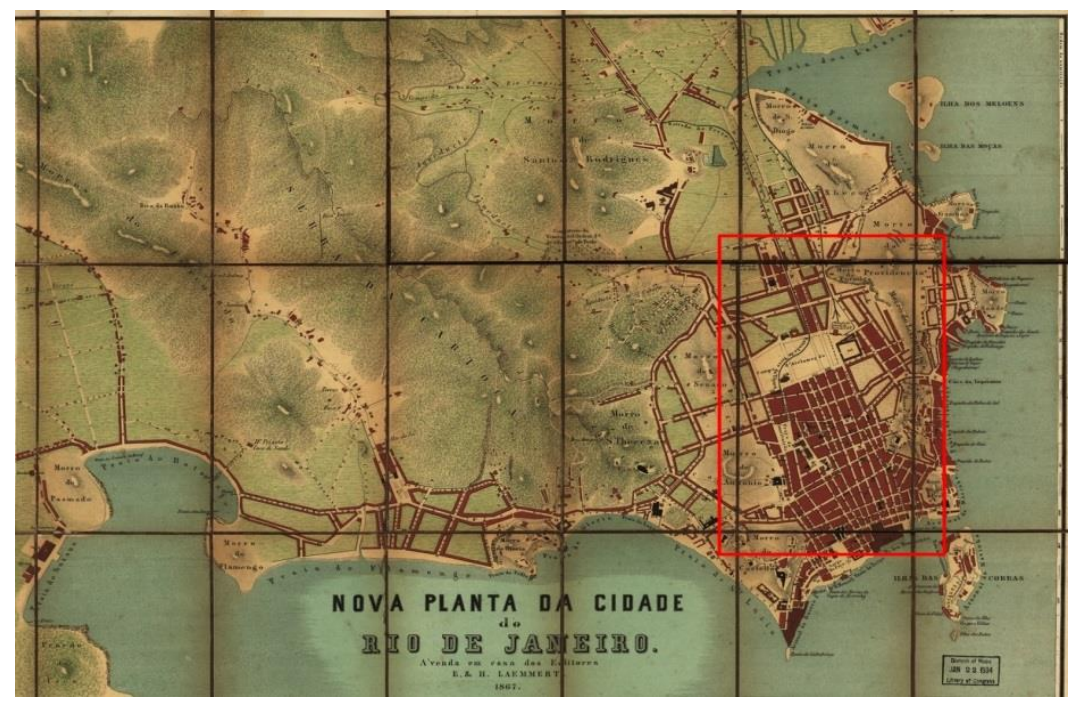

Machado de Assis em seus contos remete a zona central do Rio de Janeiro, que sendo sede de modernidades urbanísticas, “[...] contraditoriamente, mantinha também a sua condição de local de residência das populações mais miseráveis da cidade. Estas, sem nenhum poder de mobilidade, dependiam de uma localização central, ou periférica ao centro, para sobreviver" (Abreu, 2006: 42). 


\section{MAPA 02 - Territorialidade dos Contos de Assis ${ }^{5}$}

AUTOR DESCONHECIDO. Nova planta da cidade do Rio de Janeiro. Rio de Janeiro: A'venda em casa dos editores, E. \& H. Laemmert, 1867. 1 mapa : col., 41 x $54 \mathrm{~cm}$. Escala não especificada. Disponível em: <http://memory.loc.gov/cgi-bin/query/h?ammem/gmd:@ fie ld\%28NUMBER+ @ band \%28g5404r+br000055\%29\%29>. Acesso em: 22 out. 2012.

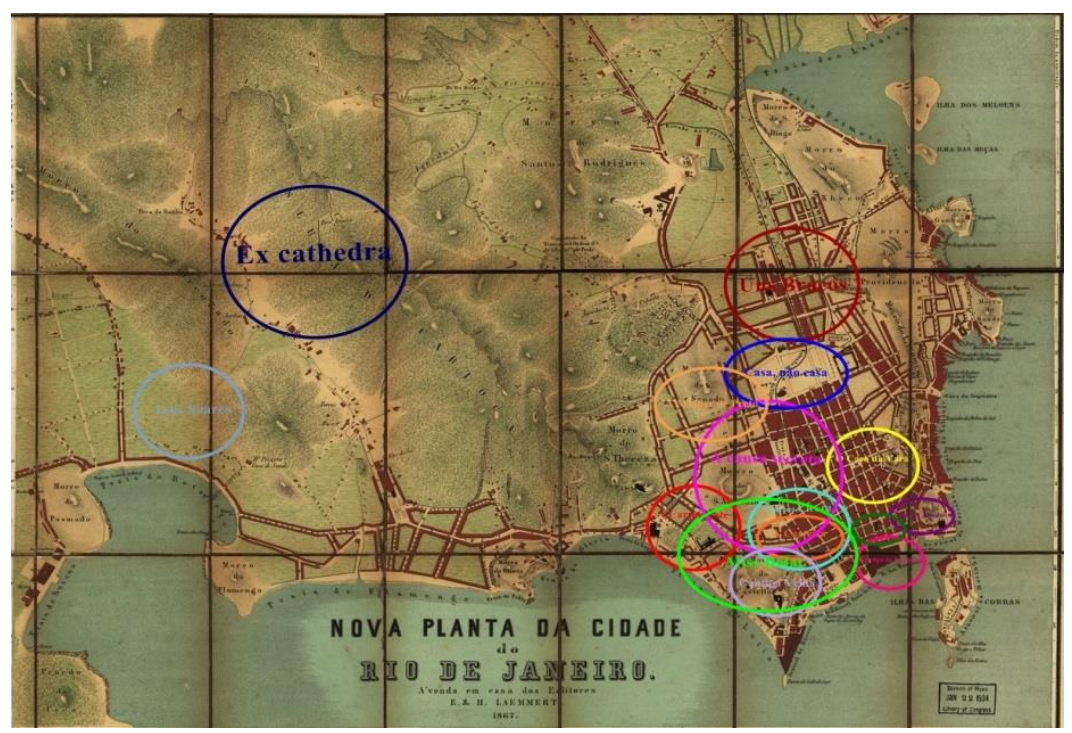

A "simpleza antiga" machadiana, apresentada pelo escritor por meio da interação entre o "tempo da cidade" e o "tempo das personagens", servem de subterfúgio para aguerrir que o progresso e a modernização da cidade aliada a uma política higienista - que resultou

5 A Nova planta da cidade do Rio de Janeiro encontra-se disponível em domínio público por meio da página The Library of Congress: American Memory (http://memory.loc.gov/cgi-bin/query/h?ammem/gmd:@ field \%28NUMBER+@band\%28g5404r+br000055\%29\%29). As marcações indicadas são acréscimos realizados por nós, a fim de demarcar o levantamento realizado acerca do perímetro e da territorialidade compreendidos pelas obras de Machado de Assis aqui analisadas. 
em uma inversão dos polos urbanizados da província fluminense podem ter contribuído para o posicionamento de Machado em relação às transformações que decorreram no Brasil oitocentista. Com o escopo de fazer uma crítica, o Rio de Janeiro machadiano é apresentado por meio das rótulas, pelas quais o progresso se torna imperceptível.

\section{Considerações finais}

Como vimos Machado de Assis ao se posicionar de forma saudosista em relação aos tempos do Imperador nos apresenta um Rio de Janeiro pulsante e que desafiava o progresso. As rótulas em suas obras evidenciam o posicionamento do literato que contrapôs em sua obra duas cidades distintas no tempo e espaço. Assis procurou incorporar criticamente a sua percepção sobre o Rio de Janeiro oitocentista nas obras analisadas e, por conseguinte, transformou seus livros em uma fonte rica para a análise histórica. Nas palavras do autor,

... Mas deixai pingar os anos na cuba de um século. Cheio o século, passa o livro a documento histórico, psicológico, anedótico. Hão de lê-lo a frio; estudar-se-á nele a vida íntima do nosso tempo, a maneira de amar, a de compor os ministérios e deitá-los abaixo, se as mulheres eram mais animosas que dissimuladas, como é que se faziam eleições e galanteios, se eram usados xales ou capas, que veículos tínhamos, se os relógios eram trazidos á direita ou á esquerda, e multidão de coisas interessantes para a nossa história pública e íntima. Daí a esperança que me fica, de não ser condenado absolutamente pela consciência dos que me leem - Machado de Assis (apud Carrer, et. tal., 1999: 09).

Machado de Assis conhecia o potencial de sua obra e talvez por isso suas impressões sejam tão ricas e interessantes. Admitir isso pode 
nos colocar em uma posição problemática, daquele que tem uma aproximação muito grande com a fonte e nem sempre consegue fazer a crítica como se deve, ainda assim é preciso tentar. Não cabe aqui dizer que, por Assis ser crítico às transformações políticas e sociais e a expansão desenfreada no Rio de Janeiro de seu tempo, seja ele também um revolucionário libertário. Parece evidente como o autor podia questionar e compactuar com os processos de seu tempo.

A crítica sem dúvida faz-se visível e mesmo sua ausência poderia ser uma forma de inferir algo, de remeter a um saudosismo em relação aquele Rio de Janeiro humano que se perde, com a estranha percepção de que a cidade cresce e seus habitantes, acostumados a viver em determinados lados dela, são cada dia mais estrangeiros.

A relutância de Assis é, portanto, perceptível, pois, somos apresentados a uma cidade que através de suas rótulas parece não ver os bondes, ou quando os vê percebe que "tudo é maravilhoso, enquanto o bonde desliza 'ao sofro da brisa invisível e amiga', mas os burros, desempregados, terão a 'liberdade de apodrecer'" (Carrer, et. tal., 1999: 18).

Podemos aqui, apenas inferir os motivos dessas ausências em Machado de Assis a partir de sua ironia sempre marcante, das sutilezas de um escritor que não precisa dizer de forma banal para ser compreendido. É possível que jamais saibamos suas reais intenções, entretanto, uma obra não é de interesse apenas para compreender a intenção do autor, mas, sobretudo, para ver o que já se foi por meio do olhar de um outro absolutamente sensível, a ponto de criar tal panorama 
histórico. A utilidade de suas obras para enxergar um pouco dos ambientes cariocas da segunda metade do século XIX é inegável e, ainda que sua riqueza fosse somente essa, já seria imensamente relevante.

\section{Fontes consultadas}

ASSIS, Machado de. Contos. Coleção Grandes Leituras. São Paulo: FTD, 2002.

. Bons dias!. Domínio público, versão e-book. Disponível em: <http://www.dominiopublico.gov.br/download/texto/bv000167.pdf>. Acesso em: out. 2012.

. Esaú e Jacó. Domínio Público, versão Ebook. Disponível em: <http://www.dominiopublico.gov.br/download/texto/bn000030.pdf>. Acesso em out. 2012.

. Obra Completa. Rio de Janeiro: Nova Aguilar, 1994. Vol. II. Publicado originalmente em Gazeta Literária, em 15/10/1883.

\section{Referências bibliográficas}

ABREU, Maurício de. Evolução Urbana do Rio de Janeiro. Rio de Janeiro: IPP, 2006. Cap. 3 e 4. pp. 35-91.

BASTIDE, Roger. Machado de Assis, paisagista. Revista do Brasil, n. 29. Rio de Janeiro: 1940.

CARRER, Aline; GLEDSON, John; MENEZES, Pedro da Cunha e. Rio de Assis: imagens machadianas do Rio de Janeiro. Rio de Janeiro: Casa da Palavra, 1999.

COSTA, Suely Gomes. "Tornando a "simpleza antiga". Rio de Janeiro, fins do Século XIX”. Revista Tempo, 2007, pp. 173-193. 
PINTO JUNIOR, Rafael Alves. "A dimensão afetiva do espaço construído: vendo a casa pelos olhos da poesia". Pós. Revista de pósgraduação em Arquitetura e urbanismo, v.16, n.25. São Paulo: FAUUSP: 2009.

SANTOS, Fabio Muruci. A paisagem oculta: desvendando o Rio de Janeiro do Quincas Borba de Machado de Assis. Revista Letras, n. 60. Curitiba: UFPR, 2003, p. 179-80.

. O punhal de Martinha: O Rio de Janeiro nas crônicas de Machado de Assis. Anos 1990, n. 14. Porto Alegre: 2000.

Recebido em: 29/04/2014 Aceito em: 08/12/2014 